\title{
THE USE OF TIME IN STORYTELLING*
}

\author{
S ABINE KOWAL \\ Technical University Berlin \\ RICHARD WIESE \\ Duesseldorf University \\ DANIEL C. O'CONNELL \\ Loyola University of Chicago
}

\begin{abstract}
A total of 18 experimental corpora of spontaneous speech in five languages (English, Finnish, French, German, and Spanish) were examined under the hypothesis that they are characterized by commonalities in the use of time. Each study was based on the same speech type, story telling elicited by pictorial materials. The temporal measures were speech and articulation rates, pause duration, phrase length, and percentage of pause time/total time. The hypothesis was confirmed except for studies carried out with identifiably variant methodologies. Further support for the hypothesis was found by contrasting the use of time characteristic of interviewees' speech.
\end{abstract}

Temporal phenomena have come to assume an important role in research on speech production as the relationship of various independent variables to these phenomena has gradually become known. Among the independent variables, age (e.g., Starkweather, 1980; Kowal, O'Connell and Sabin, 1975) and foreign language proficiency (e.g., Wiese, 1983) are perhaps the most obvious. Differential use of time has typically been interpreted in terms of the various cognitive demands involved in speech production. Although speech type has clearly been acknowledged to be an important independent variable, it is not as yet clear how narrowly a speech type must be operationally defined in order to yield temporal data that can be replicated. As long as speech type categories as broad as reading and spontaneous speech are used, the purpose of replicability and predictability will not be attained. On the other hand, if the speech type category yields replicable data only for a trivially narrow subset of experimental situations, again it becomes a useless category.

It is the thesis of the present study that there is indeed a middle ground where the category of speech type becomes a useful tool for prediction of temporal data in experimental research. Dialogue, to take but one example, would appear to be far too broad a speech type because it is subject to tremendous variation in temporal dimensions. However, it may well be that the narrower terms conversation and interview or the subcategories of interviewers' and interviewees' speech would sufficiently delimit temporal variability while still remaining useful types for purposes of prediction.

At the very least, the logic that generalizes to temporal characteristics of human speaking without any reference to specific speech types as independent variables would

* The authors wish to express their gratitude to Annerose and Doris Goerge for their help in translating this paper from German. 
seem implausible. Thus, Hörmann (1981) states without any qualifications whatsoever, "Pauses make up almost half of the entire time of speaking" (p. 118; our translation from the German); and Butterworth (1973, p. 773) contends, "If speech is so fluent that it contains less than 20 per cent silence, then it is either recitation or unconsidered ramblings." Grosjean, Grosjean, and Lane $(1979$, p. 58) generalize to the effect that "The performance structures of sentences are not task specific." Indeed, inordinate generalization beyond the operationalized speech types of a given experimental investigation can well be said to characterize current psycholinguistic research on temporal phenomena in speech.

Experimental story telling in many respects provides an excellent test case for our thesis. The task itself is easily operationalized; in the following our considerations are limited to stories elicited by pictorial materials (pictures, cartouns, and tılms) to the exclusion of verbal materials. The speech production and temporal phenomena are therefore closely stimulus-related, and dialogic, audience, rhetorical, and emotional factors are likewise minimized by the setting. Furthermore, the stories are long enough for reliable analysis, but short enough to be manageable. Finally, there are more published experimental investigations of story telling than of any other adequately operationalized speech type. The concept of story telling is used here without prejudice to the fact that some of the speech data to be considered can be labeled descriptions rather than stories in any narrative sense.

The procedure in the following is not empirical in the sense that additional data are collected and analyzed with a specific hypothesis in mind. Rather, a set of published studies is critically analyzed with the hypothesis that story telling as defined above is a speech type characterized by specific temporal patterning and is therefore a useful predictive tool. The temporal pattern must therefore be replicable from story to story but distinctive in comparison to other speech types.

In order to exclude a multitude of other independent variables, data from developmental (e.g., Levin and Silverman, 1965; Levin, Silverman and Ford, 1967; Hawkins, 1971; Sabin, Clemmer, O'Connell and Kowal, 1979), second-language (Deschamps, 1980; Raupach, 1980; Wiese, 1983), aphasic (Quinting, 1971), and schizophrenic (Rochester, Thurston and Rupp, 1977; Clemmer, 1980) research are not included. However, data from these studies for normal adult control subjects are included as indicated below.

The hypothesis is tested as follows: First, the individual studies are presented along with their purpose and important methodological details regarding pause measurement. Among these is the use of cut-off points of various lengths to determine minimum duration of pauses. Data for the various temporal variables are brought together in an overview. Then the arguments in favor of use of time specific to story telling are developed: First, deviant data are excluded on the basis of methodological and statistical criteria, and the subset of data characterizing use of time in story telling is retained. Secondly, these normative data are contrasted with another speech type (interviewees' speech). 


\section{THE EXPERIMENTAL STUDIES}

The research of Henze (1953) derives from the tradition of Ausdruckspsychologie and from the hypothesis that emotion, thought, and social intention influence rate of speech in various situations. Story telling was elicited by a film. Henze specified no minimum cut-off point for pause duration.

The classical research on story telling, however, is that of Goldman-Eisler (1961a, $1961 \mathrm{~b}, 1961 \mathrm{c}, 1961 \mathrm{~d}, 1961 \mathrm{e}, 1968)$. The research concerned the relationship between thinking and spontaneous speech in description and interpretation of cartoons. More specifically it was concerned with the question of whether speech pauses reflect difficulties in formulating thoughts and expressing them. Goldman-Eisler (1961d) assumed that descriptions involved only the sequential exposition of the pictorially presented information, while interpretations were more demanding in that they necessitated a mental reorganization of the materials as presented in order to derive a meaning.

Goldman-Eisler presented to each of nine experimental subjects a total of nine different cartoons. The subjects were first to describe the cartoons and then express the generalized significance or moral of the story as briefly as possible. In the following, only the results for the descriptions will be considered. The interpretations are excluded, as are also those in other studies (e.g., Rochester et al., 1977), because they do not fulfil the operational definition of story telling given above.

In a context of clinical psychology, Siegman and Pope (1966) investigated the relationship between ambiguity (in TAT pictures) and fluency of speech. Among the indicators of fluency was the so-called silence quotient (the ratio of pause/speech time). Except for the minimum pause duration of $3 \mathrm{sec}$, no further details regarding the method of pause measurement were given.

Lay and Paivio (1969) investigated the effects of cognitive (task difficulty) and emotional (fear of speaking before an audience) variables on extra-linguistic aspects of speech. Their assumption was that the description of cartoons (as in Goldman-Eisler, 1961d), in comparison to the simple task of describing people (age, sex, etc.) and the complex task of interpreting proverbs, was of moderate difficulty. The authors acknowledged that their recordings were of poor quality. Pause analysis was instrumental, with a 1 sec cut-off point for minimum duration. Speech rate was measured with a stopwatch.

Quinting (1971) set out to check the findings of Maclay and Osgood (1959) on the distribution of silent and filled pauses preceding content and function words respectively. Quinting had aphasic and normal subjects describe 38 unrelated pictures and considered the data as continuous story telling; only data of normal subjects are included here.

Grosjean and Deschamps' (1973) and Deschamps' (1980) research, derived directly from Goldman-Eisler, elicited descriptions of two cartoons from French speaking students.

Lass and Clegg (1973) investigated the effect of pictorial as opposed to verbal stimulus materials by instructing subjects to speak for two minutes. Only data elicited by TAT pictures are included here. 
In the tradition of Maclay and Osgood (1959) and Goldman-Eisler (1968), Kowal, O'Connell and Sabin (1975) and Sabin (1976) investigated age-dependent changes in temporal variables and vocal hesitations in story telling elicited by cartoons. Only the data for adult subjects are used in the following, with mean ages of 18 (Kowal et al.), 21, and 50 (Sabin).

Barik (1977) analyzed the temporal variables from a variety of speech situations. Only the story telling elicited by TAT pictures is considered here.

The production of coherent speech was investigated by Rochester, Thurston, and Rupp (1977). Both schizophrenic and normal subjects were used. Only the data of normal subjects are considered. The design was cartoon description, a partial replication of Goldman-Eisler (1961d).

De Johnson, O'Connell and Sabin (1979) compared English and Spanish speaking teenagers (average age of 17 years) whose story was elicited by a film with or without soundtrack, or by the soundtrack alone. Since the mode of presentation affected only the length of the story, data for the different temporal variables are combined here over all experimental conditions.

Lehtonen (1979) elicited stories from Finnish students in their native language. The stimulus materials were cartoons.

Siegman (1979) replicated Goldman-Eisler's description and interpretation of cartoons and investigated the effect of various instructions on the temporal aspects of story telling. In Experiment I, subjects described some cartoons and interpreted others. In addition, they described TAT pictures (P1) or told stories about other TAT pictures (P2). Other subjects were instructed to be as concise as possible, but the instruction had no effect on any temporal variables. In Experiment II, the description (P1) and story telling (P2) from TAT pictures were repeated with additional pictures. Siegman's calculation of speech rate excluded pauses of $>2 \mathrm{sec}$ duration from the determination of total time. No reason for the decision was given.

Hänni (1980) questioned the assumption of Goldman-Eisler (1968) that pauses are necessary for semantic, syntactic, and lexical planning. He argued that, if speech pauses were needed to make cognitive processes fossible, then acoustic disturbances during these pauses would impede speech. Hänni's subjects either commented during a silent cartoon film or told the story afterwards. In an experimental group, speech pauses were automatically filled with spoken input through earphones. In the following, only the data of subjects who told the story after the film and without spoken input during their pauses are included.

Raupach (1980) had German and French students describe and interpret a pictorial story in their native tongue. Immediately afterwards, they described and interpreted the same story in their respective foreign languages. Raupach did not analyze descriptions and interpretations separately. Only the native language data are included here.

Kowal and Wiese (1981) analyzed temporal variables in story telling elicited by a film (Chafe, 1980).

Wiese (1983) elicited stories from English and German students with a set of cartoon pictures. His independent variables were language (German and English), language fluency (L1 and L2), and mode of presentation (presence or absence of cartoon during story telling). Again, only data of native speakers are considered here. 


\section{THE DATA BASE}

In the research on temporal variables in speech, many different response measures have been used to characterize the flow of speech. A direct comparison of the results of various experiments is, therefore, possible to only a limited extent. For the present comparison of data, we have chosen six response measures: speech rate $(\mathrm{syl} / \mathrm{sec})$, articulation rate (syl/sec), pause duration (sec), phrase length (syl/pause), and percentage of pause time/total time.

Published data have been recast, wherever necessary and possible, and summarized in these terms in Table 1. Recast response measures are indicated there by superscripts. In addition to the temporal variables, average length of speech samples is included in Table 1. Where authors expressed sample length in number of words, their data have been recast into number of syllables from the following estimates: $1.23 \mathrm{syl} /$ word for English (averaged from de Johnson et al., 1979; Kowal et al., 1975; Sabin, 1976; and Wiese, 1983); $1.29 \mathrm{syl} /$ word for French (Grosjean and Deschamps, 1973); $1.71 \mathrm{syl} /$ word for Spanish (de Johnson et al., 1979); 1.38 syl/word for German (Wiese, 1983). Also included in Table 1 are the number of experimental subjects, the language used in the experiment, the choice of pictures (P), cartoons (C), or film (F) as stimulus materials, and the minimum cut off points adopted for pause duration (sec).

A cut-off point has traditionally been considered necessary, since short periods of silence are required for articulation. In order to separate these articulatory pauses from those with other (psychological and interactive) functions, minimum pause durations of 0.2-0.31 sec have been adopted after the precedent of Goldman-Eisler. If such a minimum duration is not adopted at all or is set considerably higher than $0.3 \mathrm{sec}$, changes are introduced into all temporal measures to be used here, with the exception of speech rate (see also Braehler and Zenz, 1975; Butcher, 1981; O'Connell, 1980; Rochester, 1975/76). Hieke, Kowal and O'Connell (1983) have recently challenged the articulatory rationale for cut-off points higher than $0.13 \mathrm{sec}$, but also acknowledged instrumental problems of measurement for shorter durations.

\section{ANALYSIS AND DISCUSSION}

The contents of Table 1 make it clear that there is commonality across the majority of the studies in temporal patterning. Two criteria are applied to decide whether deviant data are to be excluded from further discussion. The first criterion for exclusion is the use of pause measurement that is clearly different from that of the other studies and to which the deviation of the data in question can be ascribed. The second is the statistical improbability that an excessively deviant sample belongs to the same population as the other data. The remaining subset of studies is then compared with interviewees' speech.

\section{The criterion of minimum cut-off point}

Of the 18 investigations included in Table 1,14 use a minimum pause duration between 0.2 and $0.31 \mathrm{sec}$. Deviations from the original value of $0.25 \mathrm{sec}$ suggested by 
总贾点

它方㝵

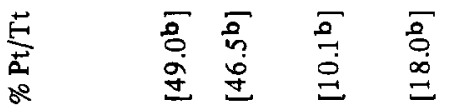

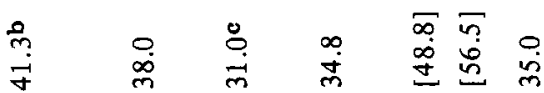

के

范兽

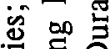

㤩

㟧要

吉范

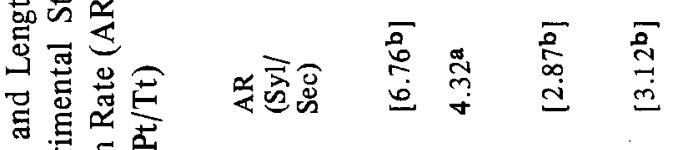

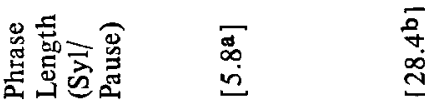

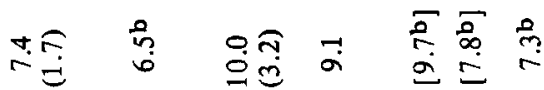

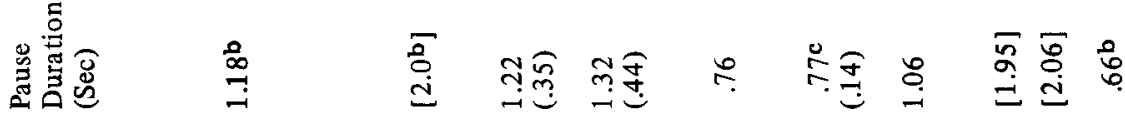

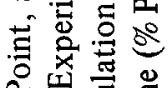

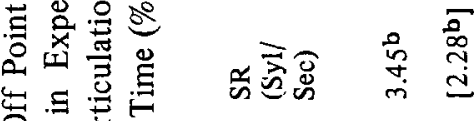

$\stackrel{\infty}{2}$

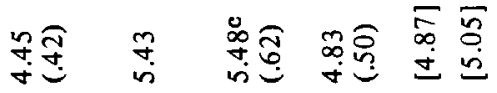
至过文

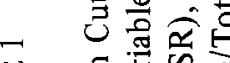

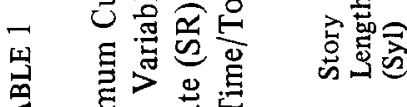

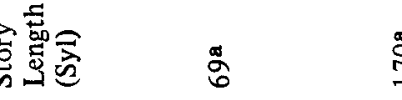

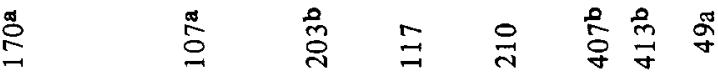

矛芯

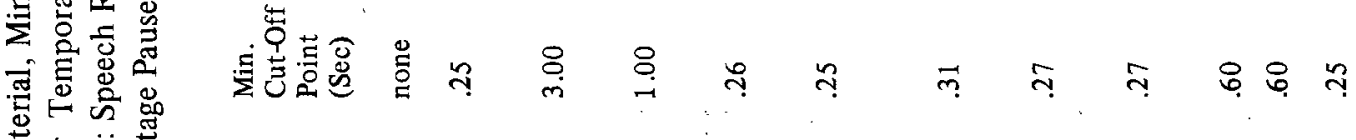
. .

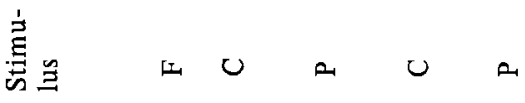

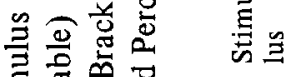
焉焉的票

थ 2 过

密总

需 $\frac{1}{3}$

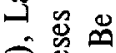

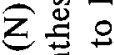

苍造

窵

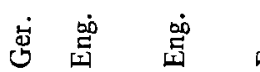

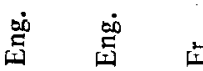

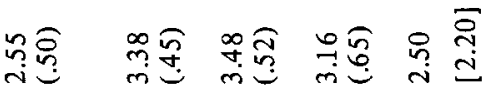

手秀

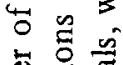

농 옹

范㞼志

之.

z

8 a

요

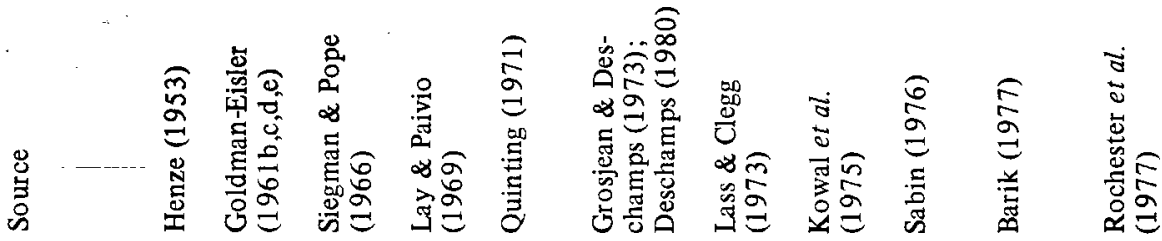




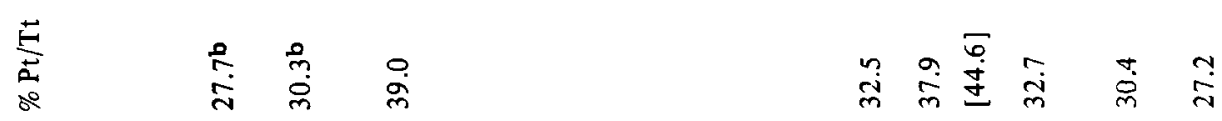

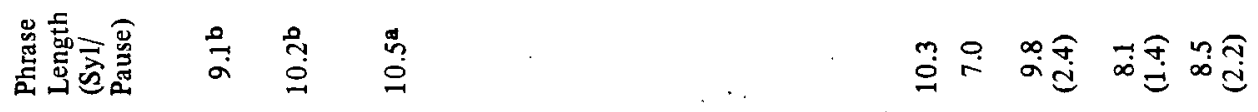

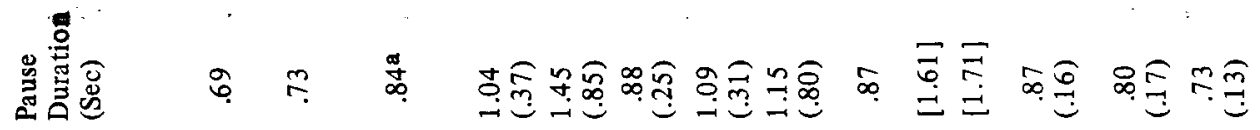

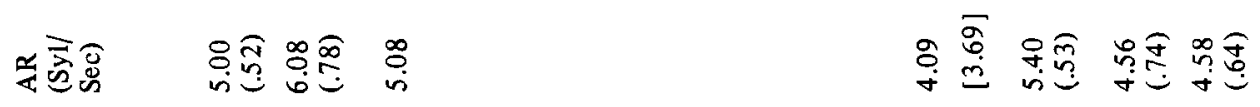

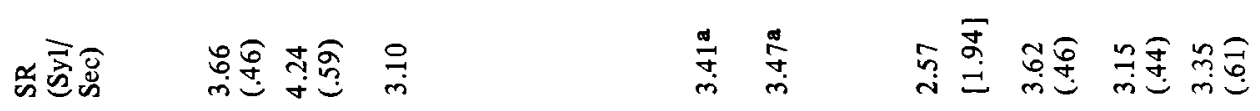

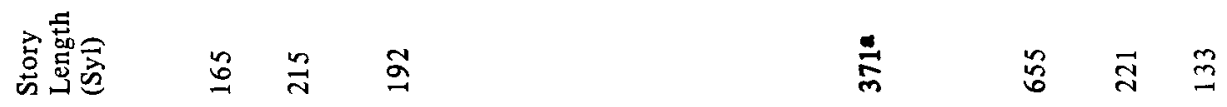

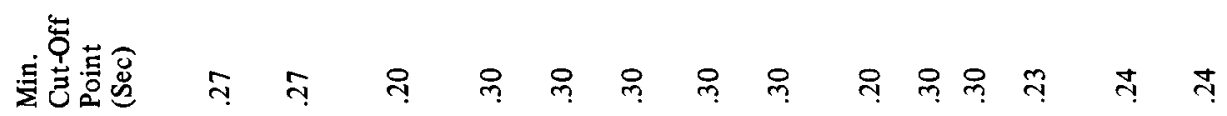

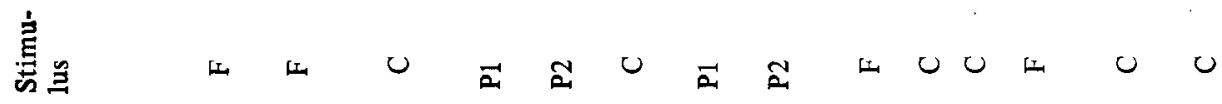

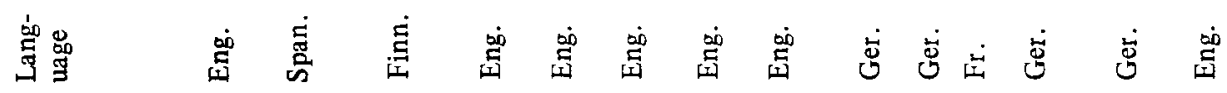

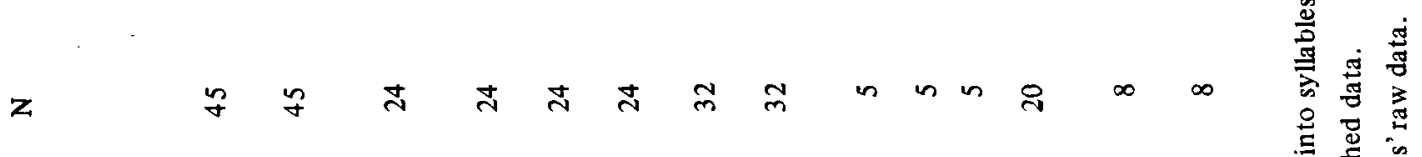

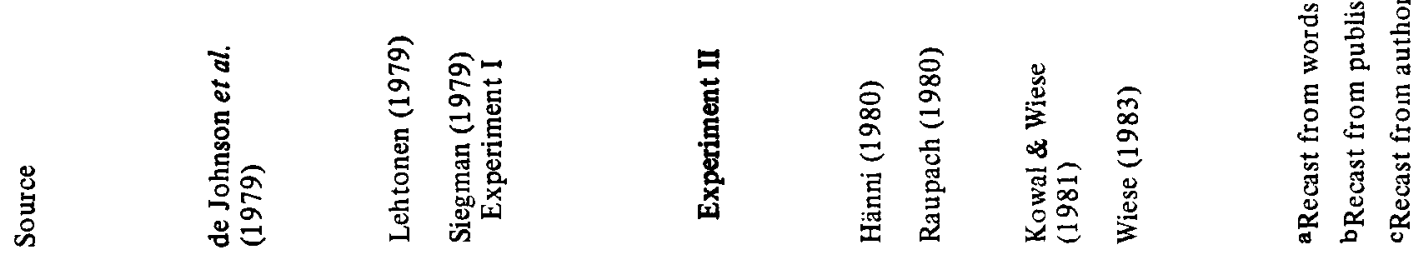


Goldman-Eisler have no theoretical justification, but are due rather to instrumental limitations.

In Siegman and Pope (1966), Lay and Paivio (1969), and Barik (1977), on the other hand, considerably higher minimum pause durations are adopted, while in Henze (1953) no minimum cut-off point is indicated. Henze's comment that pause duration was calculated within as well as between words suggests that considerably shorter pauses were indeed included in his data.

The consequences of adopting a minimum cut-off point well above $0.25 \mathrm{sec}$ are numerous. Goldman-Eisler (1968, p. 14) and Grosjean and Deschamps (1973, p. 207) found that $71.5 \%$ and over $50 \%$, respectively, of all pauses occur in the duration interval between 0.25 and $1 \mathrm{sec}$. A considerably higher cut-off point excludes part (or all) of these pauses, lowers the percentage of pause time/total time, lengthens mean pause duration and increases mean phrase length, and finally yields a slower articulation rate - all quite independently of any real change in the data.

Accordingly, the data of Siegman and Pope (1966) and Lay and Paivio (1969) in Table 1 are all shifted in the expected directions. On the other hand, Barik (1977), using a minimum pause duration of $0.6 \mathrm{sec}$, found a surprisingly high $48.8 \%$ of pause time/ total time. Had he used a minimum cut-off point within the range of $0.2-0.31 \mathrm{sec}$, his percentage of pause time/total time would necessarily have increased to around $60 \%$.

The consequences of adopting no minimum cut-off point are also serious. A frequency distribution of pauses from Glukhov (1975; cited in O'Connell, 1980, p. 33) shows that pauses of the shortest durations $(0.05-0.15 \mathrm{sec})$ occur most frequently in all the languages sampled (English, French, German, Italian, Portuguese, and Spanish). Inclusion of all these short pauses increases the percentage of pause time/total time and accelerates articulation rate. These shifts are exactly what one finds in Table 1 for Henze's (1953) data.

One must conclude, therefore, that the data of Henze (1953), Siegman and Pope (1966), Lay and Paivio (1969), and Barik (1977) differ artifactually from those of the other studies presented in Table 1 , with the exception that speech rate remains unaffected by cut-off point and therefore comparable. All the data with the exception of speech rate have therefore been excluded from further consideration.

\section{The criterion of normal distribution}

If one assumes that the data in Table 1 (excluding the data indicated above) are from the same population, and normally distributed, then they should not be expected to deviate more than two standard deviations in either direction from the mean with a confidence coefficient of $95 \%$. The following additional data are excluded in accordance with this criterion: Goldman-Eisler (speech rate, phrase length, percentage of pause time/total time); Barik (speech rate in French); Raupach (speech rate in French, articulation rate in French, pause duration in German and French, and percentage of pause time/total time in French).

A further examination of the studies by Goldman-Eisler, Barik, and Raupach will throw light on the reasons underlying their statistical deviation from the remaining data. 
All three sets of data deviate in the direction of slower speaking: Speech rates and articulation rates are slower, and phrase lengths shorter; percentages of pause time/total time are higher, and pause durations longer. Since these commonalities of the three sets of data could possibly reflect a real deviation from the other data in Table 1, despite overall commonalities of experimental conditions, the three sets of data must be further examined for artifactual determinants. Otherwise, the thesis of a use of time characteristic of story telling elicited by pictorial materials is in jeopardy.

In Goldman-Eisler (1961d), the artifact is to be found in her operational definition of words in a way that clearly differs from the rest of the studies in Table 1. All "irrelevant vocal productions, i.e. noise, such as repetition of the same words or other obvious forms of marking time vocally" (p. 167) are excluded from her word counts, but nonetheless enter into the determination of total time. This decision necessarily yields a slower speech rate and shorter phrase length, and correspondingly a higher percentage of pause time/total time, since the time of the "irrelevant vocal productions" is automatically relegated to pause time.

In Barik (1977), a similar artifact is to be found that contributes to an unusually slow speech rate. Without explaining why, he counted "filled pauses ('uhs') and other 'noise'" (p. 118) as pause time. This procedure diminished the number of syllables and consequently yields a slower speech rate and a higher percentage of pause time/total time. Hence, despite his use of a high cut-off point $(0.6 \mathrm{sec})$ to define pauses, he found a high percentage of pause time/total time.

In Raupach (1980), details of experimental procedures and data analysis were not given. His decision to combine data from descriptions and interpretations could plausibly be expected to yield measures of slower speaking. It should be recalled that the present authors have excluded data from interpretations from their analyses of all other studies. Raupach's Table 1 (p. 265) also reveals a very small sample of subjects with extreme variation in response measures.

The data remaining after application of the two exclusion criteria are included in Table 2. The weighted means and standard deviations are based on the number of experimental subjects indicated in the table and, as population estimates, provide empirical norms for the respective temporal variables for story telling in five different languages. Also included in Table 2 are weighted means and standard deviations for interviewees' speech to be discussed below.

In summary, then, the exclusion criteria yield a subset of data that can be characterized by specific patterning in the use of time for story telling. The problems involving a minimum cut-off point for pause duration (the first exclusion criterion) concerned primarily off-time and have been engaged straightforwardly. The problems involved in variant definitions of on-time elements, however, have been approached statistically (the second exclusion criterion) and have been identified only on a post factum basis. In both cases the methodological problems are equally serious although the on-time problems prove more difficult to discover. The astounding finding is that GoldmanEisler's are among the excluded data. Researchers have been very acutely aware of the importance of a minimum cut-off point, as was Goldman-Eisler herself; definitions which profoundly affect on-time (textual) components have easily escaped notice. 
TABLE 2

Number of Experimental Subjects $(N)$, Weighted Means $(M)$, and Standard Deviations $(S D)$ of Temporal Variables for Story Telling after Application of Exclusion Criteria to Data in Table 1 and for Interview Data in Table 3

\begin{tabular}{|c|c|c|c|c|c|c|}
\hline & \multicolumn{3}{|c|}{ Story Telling } & \multicolumn{3}{|c|}{ Interview } \\
\hline & $N$ & $M$ & $S D$ & $N$ & $M$ & $S D$ \\
\hline $\begin{array}{l}\text { Speech Rate } \\
(\mathrm{Syl} / \mathrm{Sec})\end{array}$ & 413 & 3.43 & .43 & 69 & 4.31 & .10 \\
\hline Articulation & & & & & & \\
\hline Rate $(\mathrm{Syl} / \mathrm{Sec})$ & 273 & 5.17 & .53 & 69 & 5.26 & .14 \\
\hline $\begin{array}{l}\text { Pause Duration } \\
\text { (Sec) }\end{array}$ & 437 & .94 & .23 & 69 & .53 & .06 \\
\hline $\begin{array}{l}\text { Phrase Length } \\
\text { (Syl/Pause) }\end{array}$ & 289 & 9.0 & 1.3 & 69 & 13.5 & 1.3 \\
\hline $\begin{array}{l}\text { Percentage of } \\
\text { Pause Time/ }\end{array}$ & & & & & & \\
\hline Total Time & 289 & 33.3 & 4.2 & 69 & 17.2 & 2.7 \\
\hline
\end{tabular}

\section{Comparisons with interviewees' use of time}

Temporal analyses of interviewees' speech are available from three studies. GoldmanEisler (1956) recorded interviews from five patients and three staff members of a hospital. Grosjean and Deschamps (1975) sampled from British and French radiointerviews; interviewees included artists, journalists, politicians, and union leaders. The minimum cut-off point for the measurement of pause duration was $0.25 \mathrm{sec}$. Duez (1982) analyzed televised and broadcast interviews of five leading French politicians during election campaigns. The two interview types included were political and casual, depending upon whether the topic discussed involved the ongoing political campaign or biographical matters. Duez' minimum cut-off point varied from 0.18 to $0.25 \mathrm{sec}$, depending upon speaker characteristics.

Goldman-Eisler (1956) did not specify operational details of pause measurement. If one assumes that the same methodology was used as in her story telling research (1961d), the two sets of data are comparable only to one another. Such a comparison indicates that speech rate is faster $(3.29>2.28 \mathrm{syl} / \mathrm{sec})$ and percentage of pause time/total time considerably lower $(32.5<46.5 \%)$ in the interviews than in the story telling. The results of Grosjean and Deschamps (1975) and Duez (1982) are summarized in Table 3. Weighted means and standard deviations based on their data are summarized in Table 2 . 


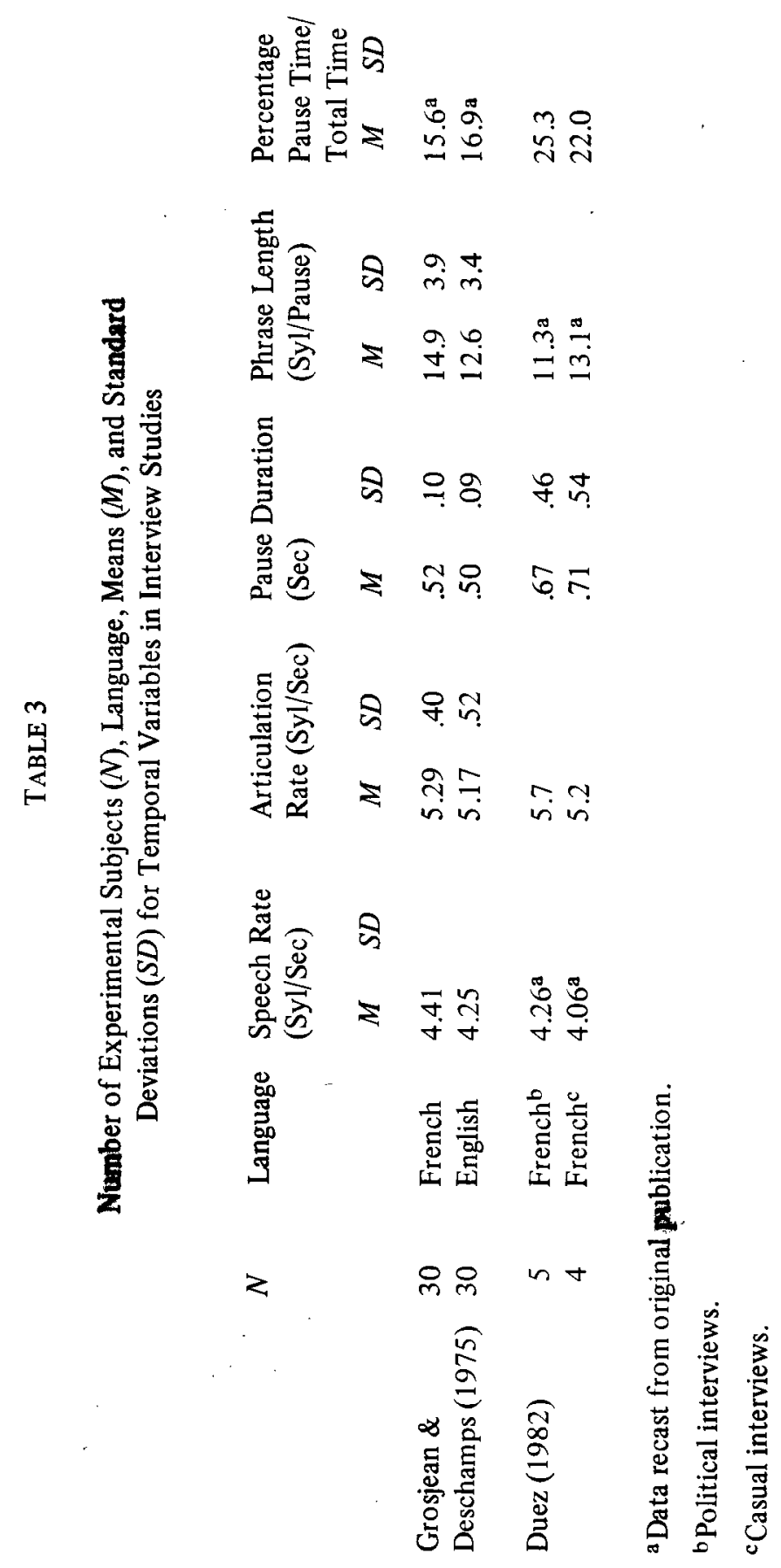




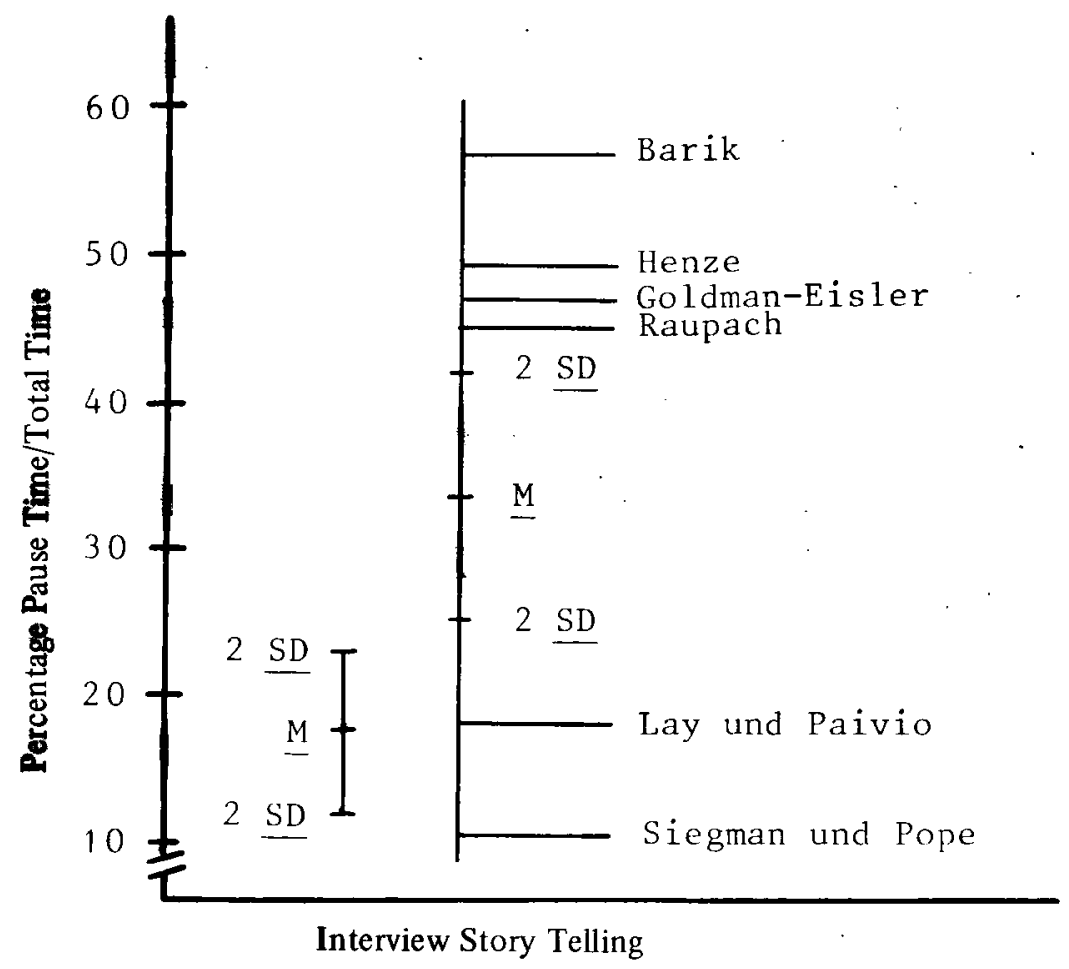

Fig. 1. Overall Means $(M)$ and Standard Deviations $(S D)$ for Percentage Pause Time/ Total Time of Data in Table 2; Means for Excluded Story Telling Data.

A comparison of story telling and interviewees' speech shows the same relationships as those observed with Goldman-Eisler's data. Because the articulation rates for the two speech types are similar (5.17 and $5.26 \mathrm{syl} / \mathrm{sec}$ respectively), it is clear that differences in the other response measures reflect off-time differences only. The most pronounced of these off-time differences is in percentage of pause time/total time: Story tellers use on the average almost twice as much off-time as interviewees. There is no overlap in the estimated population distributions for the two speech types. The two other off-time measures both contribute in turn to percentage pause time/total time, but neither manifests complete non-overlap of the two speech types. Similarly, speech rate for the two speech types is quite different, but there is a small overlap in the distributions.

To return finally to the comparison of Goldman-Eisler's interview and story telling data, the respective percentages of pause time/total time (32.5 and $46.5 \%$ ) clearly do not fit with the data from the majority of the studies in Tables 1 and 3 . Nonetheless, if a simple assumption is made, namely, that the amount of the constant error due to her idiosyncratic operational definition of words is such as to place the true interview percentage at the weighted mean for the interview percentages in Table 2 , then the true 
percentage (31.2\%) for her story telling data would accordingly fall quite close to the weighted mean percentage for story telling in the same table.

In summary, then, the thesis of the present study - that use of time is a legitimate experimental tool to characterize speech types - has been confirmed. Given an adequate operational description, experimental story telling elicited by pictorial materials proves to be homogeneous with regard to temporal variables. Deviant data can be excluded on methodological grounds. The other side of the coin is the distinction between speech types in terms of time use. The sample comparison of story telling and interviewees' speech confirms this as well. This general picture is summarized in Fig. 1 where the estimated population distributions of percentage of pause time/total time for story telling and interviewees' speech are summarized. Locations of mean data from studies that have been excluded are also shown.

\section{CONCLUSION}

The results indicate that generalized statements about use of time in speaking, referred to at the beginning of this study, are not warranted by the evidence. Some "performance structures of sentences" (Grosjean et al., 1979, p. 58) must indeed be task specific; it is highly unlikely that all differences in time use occur only between sentences. Moreover, the interview data show that it is obviously quite possible to be silent less than $20 \%$ of one's speaking time without falling into "either recitation or unconsidered ramblings" (Butterworth, 1973,p.773). The public figures whose interviews are reported in Grosjean and Deschamps (1975) and Duez (1982) were certainly expressing themselves both carefully and spontaneously. Finally, Hörmann's (1981, p. 118) claim that "pauses make up almost half of the entire time in speaking" proves to be equally groundless. Both sets of data (story telling and interview) are such that $50 \%$ pause time/total time would be more than 2 SD from the estimated population mean, as can be seen in Figure 1. It is, in fact, an open question as to whether a speaker is even capable of maintaining the train of thought and imparting a basic impression of continuity (by analogy to music, legato) with such a high percentage of off-time.

On the other hand, generalizability across languages is supported by the evidence. Whatever influence native language may have on the use of time, it is certainly negligible relative to the influence of speech type. This is evident in the data for all five languages and suggests the possibility of a language universal for time use within specific speech types. Our results are therefore not in accord with those of Haggan (1973) and Grosjean and Deschamps (1975). The latters' finding of significant differences in phrase length between English and French relies on the use of a directional inferential statistic without a directional hypothesis (see their Table 2, p. 152).

One might argue that story telling and interviewees' speech are extreme cases of speech types. The point is well taken. The extreme cases have been deliberately used to establish the importance of speech type as such. Complete non-overlap of speech types with regard to the use of time is not part of the argument and is prima facie absurd.

The underlying differences in story telling and interviewees' speech would include the 
amount of preplanning, the dialogic-monologic difference, and the cognitive constraints. In the studies presented here, an additional difference is to be found in the type of speaker; with the exception of Goldman-Eisler's study, the interviewees were public figures with experience in speaking situations, whereas the story tellers were simply adult speakers. Further research will be needed in order to separate the influence of speaker type from speech type more accurately.

Over the years methodologies involving temporal measurements have become more comparable. One indication of this development is to be found in the relatively greater number of early studies excluded from the subset used as basis for our empirical norms. But the importance of comparable methodologies must be emphasized even today if we are to avoid trivialization of research. This is not to say that there is no other way to analyze temporal dimensions of speech production. The relationship of various temporal phenomena to structural characteristics of text is, for example, a perfectly legitimate and fruitful approach, but has not been considered here. The important point to be made is that identical response measures are concerned.

A great deal more research is needed to clarify the role of time usage in various speech types. It is clear, however, that a comprehensive theory of speech production must take in to account the use of time characteristic of speech types.

\section{REFERENCES}

BARIK, H.C. (1977). Cross-linguistic study of temporal characteristics of different types of speech materials. Language and Speech, 20, 116-126.

BRAEHLER, E. and ZENZ, H. (1975). Artifacts in the registration and interpretation of speechprocess variables. Language and Speech, 18, 166-179.

Butcher, A. (1981). Aspects of the Speech Pause: Phonetic Correlates and Communicative Functions (Universität Kiel, Arbeitsbericht Nr. 15 des Instituts für Phonetik).

BUTTERWORTH, B. (1973). The science of silence. New Society, 26, 771-773.

CHAFE, W.L. (ed.) (1980). The Pear Stories: Cognitive, Cultural, and Linguistic Aspects of Narrative Production (Norwood, N.J.).

CLEMmer, E.J. (1980). Psycholinguistic aspects of pauses and temporal patterns in schizophrenic speech. Journal of Psycholinguistic Research, 9, 161-185.

DE Johnson, T., O'CONNELL, D.C. and SABIN, E.J. (1979). Temporal analysis of English and Spanish narratives. Bulletin of the Psychonomic Society, 13, 347-350.

DESCH AMPS, A. (1980). The syntactical distribution of pauses in English spoken as a second language by French students. In H.W. Dechert and M. Raupach (eds.), Temporal Variables in Speech: Studies in Honour of Frieda Goldman-Eisler (The Hague), pp. 255-262.

DUEz, D. (1982). Silent and non-silent pauses in three speech styles. Language and Speech, 25, 11-28.

GLUKHOV, A.A. (1975). Statistical analysis of speech pauses for Romance and Germanic languages. Soviet Physics: Acoustics. 21, 71-72.

Goldman-EISLER, F. (1956). The determinants of the rate of speech output and their mutual relations. Journal of Psychosomatic Research, 1, 137-143.

GOLDMAN-EISLER, F. (1961a). A comparative study of two hesitation phenomena. Language and Speech, 4, 18-26.

GOLDMAN-EISLER, F. (1961b). Continuity of speech utterance, its determinants and its significance. Language and Speech, 4, 220-231.

GOLDMAN-EISLER, F. (1961 c). The distribution of pause durations in speech. Language and Speech, $4,232-237$. 
GoldmAN-EISLER, F. (1961d). Hesitation and information in speech. In C. Cherry (ed.), Information Theory (London), pp. 162-174.

GOLDMAN-EISLER, F. (1961e). The significance of changes in the rate of articulation. Language and Speech, 4, 171-174.

Goldman-EISLER, F. (1968). Psycholinguistics: Experiments in Spontaneous Speech (London).

GrosjeAN, F. and DeschamPS, A. (1973). Analyse des variables temporelles du français spontané II. Comparaison du français oral dans la description avec l'anglais (description) et avec le français (in terview radiophonique). Phonetica, 28, 191-226.

GrosjEAN, F. and DESCHAMPS, A. (1975). Analyse contrastive des variables temporelles de l'anglais et du français: Vitesse de parole et variables composantes, phénomènes d'hesitation. Phonetica, 31, 144-184.

Grosjean, F., Grosjean, L. and LANe, H. (1979). The patterns of silence: Performance structures in sentence production. Cognitive Psychology, 11, 58-81.

HÄNNI, R. (1980). What is planned during speech pauses? In H. Giles, W.P. Robinson and P.M. Smith (eds.), Language: Social Psychological Perspectives (Oxford), pp. 321-325.

HAGgaN, M. (1973). Cross linguistic aspects of pausing. Doctoral Dissertation, University College London .

HAWKINS, P.R. (1971). The syntactic location of hesitation pauses. Language and Speech, 14, 277 288.

HENZE, R. (1953). Experimentelle Untersuchungen zur Phänomenologie der Sprechgeschwindigkeit. Zeitschrift für Experimentelle und Angewandte Psychologie, 1, 214-243.

HIEKE, A.E., KOWAL, S. and O'CONNELL, D.C. (1983). The trouble with "articulatory" pauses. Language and Speech, 26, 203-214.

HörmanN, H. (1981). Einführung in die Psycholinguistik (Darmstadt).

KOWAL, S., O'CONNELL, D.C. and SABIN, E.J. (1975). Development of temporal patterning and vocal hesitations in spontaneous narratives. Journal of Psycholinguistic Research, 4, 195-207.

KOWAL, S. and WIESE, R. (1981). Pausenverhalten in experimentellen Erzählsituationen. Unpubl. ms.

LASS, N.J. and CLEGG, J.D. (1973). Comparative study of temporal characteristics of picture-elicited and topic-elicited speech. Perceptuat and Motor Skills, 36, 995-998.

LAY, C.H. and PAIVIO, A. (1969). The effects of task difficulty and anxiety on hesitations in speech. Canadian Journal of Behavioral Science, 1, 25-37.

LEHTONEN, J. (1979). Speech ratc and pauses in the English of Finns, Swedish-speaking Finns, and Swedes. In R. Palmberg (ed.), Perception and Production of English: Papers on Interlanguage (Pubs. Dept. of English, Åbo Akademi).

LEVIN, H. and SiLvermaN, I. (1965). Hesitation phenomena in children's speech. Language and Speech, 8, 67-85.

LEVIN, H., SILVERMAN, I. and FORD, B. (1967). Hesitations in children's speech during explanation and description. Journal of Verbal Learning and Verbal Behavior, 6, 560-564.

MACLAY, H. and OSGOOD, C. (1959). Hesitation phenomena in spontaneous English speech. Word, 15,1944 .

O'CONNELL, D.C. (1980). Cross-linguistic investigation of some temporal dimensions of speech. In H.W. Dechert and M. Raupach (eds.), Toward a Cross-Linguistic Assessment of Speech Production (Frankfurt), pp. 23-38.

QUinting, G. (1971). Hesitation Phenomena in Adult Aphasic and Normal Speech (The Hague).

RAUPACH, M. (1980). Temporal variables in first and second language speech production. In H.W. Dechert and M. Raupach (eds.), Temporal Variables in Speech: Studies in Honour of Frieda Goldman-Eisler (The Hague), pp. 263-270.

ROCHESTER, S.R. (1975/76). Defining the silent pause in speech. Joumal of the Ontario Speech and Hearing Association, 8, 14.

Rochester, S.R., Thurston, S. and RUPP, J. (1977). Hesitations as clues to failures in coherence: A study of the thought-disordered speaker. In S. Rosenberg (ed.), Sentence Produc. tion: Developments in Research and Theory (Hillsdale, N.J.), pp. 65-87.

SABIN, E.J. (1976). Pause and rate phenomena in adult narratives. Master's Thesis, Saint Louis University, Saint Louis. 
SABin, E.J., Clemmer, E.J., O'ConNell, D.C. and Kowal, S. (1979). A pausological approach to speech development. In A.W. Siegman and S. Feldstein (eds.), Of Speech and Time: Temporal Speech Patterns in Interpersonal Contexts (Hillsdale, N.J.), pp. 33-55.

SiEgmaN, A.W. (1979). Cognition and hesitation in speech. In A.W. Siegman and S. Feldstein (eds.), Of Speech and Time: Temporal Speech Patterns in Interpersonal Contexts (Hillsdale, N.J.), pp. 151-178.

SIEgMAN, A.W. and POPE, B. (1966). Ambiguity and verbal fluency in the TAT. Journal of Consulting Psychology, 30, 239-245.

STARKWEATHER, C.W. (1980). Speech fluency and its development in normal children. In N. Lass (ed.), Speech and Language: Advances in Basic Research and Practice, Vol. 4 (New York), pp. 143-199.

WIESE, R. (1983). Psycholinguistische Aspekte der Sprachproduktion: Sprechverhalten und Verbalisierungsprozesse (Hamburg). 